\title{
O discurso sobre a biblioteca escolar na rede eletrônica: sentidos a perder de vista
}

\author{
The discourse on school library in the electronic network
}

\begin{abstract}
Ludmila Ferrarezi
Mestre em Psicologia pela FFCLRP/ USP.

Lucília Maria Sousa Romão

Doutora em Psicologia pela FFCLRP/USP.

Profa. Dra. do Curso de Graduação em Ciências da Informação e da Documentação da FFCLRP/ USP.

E-mail: luciliamsr@uol.com.br
\end{abstract}

\begin{abstract}
Resumo
Neste trabalho, objetivamos estudar discurso e rede eletrônica para observar como sujeitos fazem falar sentidos de biblioteca escolar, leitura e bibliotecário em uma lista de discussão e em um blog. Anotamos que memória discursiva como condição de todo dizer, sujeito como posição e discurso como efeito de sentidos entre interlocutores serão as bases conceituais que apoiarão nosso estudo. Assim, tomando os postulados da teoria discursiva fundada por Michel Pêcheux, interessa-nos interpretar um corpus coletado on-line e cujos recortes apontam a Internet como um observatório de sentidos mais plurais, dados pelos confrontos entre diferentes formações discursivas que se misturam, entre sentidos e sujeitos em movimento constante e interação, propiciada pela volatilidade da rede e pela maleabilidade do discurso.
\end{abstract}

Palavras-chave: discurso, rede eletrônica, biblioteca escolar.

\begin{abstract}
In that work we aimed at to study speech and electronic net to observe as subjects make to speak to senses of school library, reading and librarian in a discussion list and a weblog. We wrote down that discursive memory as condition of every saying, subject as position and speech as effect of senses among speakers, they will be the conceptual bases that will support our study. Like this, taking the postulates of the discursive theory founded by Michel Pêcheux, interests to us interpret a corpus collected on-line and whose cuttings point Internet as an observatory of more plural senses, given by the confrontations among different discursive formations that they are mixed, among senses and subjects in constant movement and interaction, propitiated by the volatility of the net and for the malleableness of the discourse.
\end{abstract}

Keywords: discourse, electronic net, school library.

InCID: R. Ci. Inf. e Doc., Ribeirão Preto, v. 1, n.1, p. 56-76, 2010. 


\title{
Uma entrada na roda de dizer
}

\begin{abstract}
É o que têm de bom as associações de ideias, umas vão puxando pelas outras, de carreirinha, a habilidade está em não deixar perder o fio à meada, em compreender que um caco no chão não é apenas o seu presente de caco no chão, é também o seu passado de quando não o era, é também o seu futuro de não saber o que virá a ser. - José Saramago
\end{abstract}

Ao longo de últimos cinco anos, temos nos empenhado em especular sentidos e produzir reflexões sobre a biblioteca escolar do ponto de vista discursivo, interpretando dizeres coletados na literatura científica, em leis federais, em blogs, em textualizações midiáticas, em desenhos infantis e em depoimentos orais e escritos de sujeitos-escolares sobre o tema. Por agora, entramos na rede eletrônica para observar como sujeitos fazem falar sentidos de biblioteca escolar, leitura e bibliotecário em uma lista de discussão e em um blog, sustentando-se na memória discursiva como condição do dizível. Para isso, adotamos o seguinte roteiro: inicialmente apresentaremos os postulados da teoria discursiva fundada por Michel Pêcheux, colorindo as noções de discurso, sujeito, sentido e memória discursiva. Depois, investimos nossa atenção na leitura de vários estudiosos que tematizam a rede eletrônica, destacando as novas configurações de tempo e espaço dadas durante a navegação; além disso, pontuamos como o jogo das formações imaginárias funciona nesse novo lugar discursivo em que arquivos, dizeres e palavras justapõem-se no on-line. Por fim, apresentamos nosso corpus de análise constituído por recortes de dizeres coletados em uma lista de discussão eletrônica e em um blog, dedicados à Biblioteconomia.

\section{Nas trilhas do discurso: o movimento dos sentidos}

O sentido não é capaz de permanecer quieto, fervilha de sentidos segundos, terceiros e quartos, de direções irradiantes que vão se dividindo e subdividindo em ramos e ramilhos, até se perderem de vista. - José Saramago

Para que possamos investigar os movimentos do sujeito e do discurso sobre a biblioteca escolar, materializados nas redes de sentidos fervilhantes da Internet, mobilizaremos os pressupostos teóricos da Análise do Discurso de linha francesa, 
especialmente aqueles formulados por Michel Pêcheux, para compreender de que forma eles se constituem, como o processo discursivo é inscrito na língua, e não simplesmente extrair os sentidos do texto. (ORLANDI, 2003a). Ocupamos, para tanto, uma posição intervalar, tal qual a Análise do Discurso, deslocando-nos entre as fronteiras do campo do Discurso, da Biblioteconomia e da Educação, inserindo nossa voz nos interstícios e desvãos da língua, da história e da rede eletrônica. Ao buscar colocar-se como um objeto-fronteira, a Análise do Discurso trabalha "no limite das grandes divisões disciplinares já institucionalizadas. Esta posição de entremeio quase nunca é confortável, pressupõe contínuos, deslocamentos, cruzamentos e confrontos" (FERREIRA, 2000, p. 15), que marcam a própria linguagem, sujeita às falhas e rupturas, as quais a distanciam de uma noção de regularidade, que seria compatível a um mundo lógico e homogêneo, previsível e reduzido.

Afastamo-nos, assim, de uma postura conteudista (pela qual se acredita que é possível saber o que o autor quis dizer e qual o sentido do texto), na medida em que buscamos investigar como a história se inscreve no discurso, de que maneira, na relação com o político, um objeto simbólico produz sentidos, ou seja, de que modo as relações de poder são significadas, simbolizadas, conforme nos conta Orlandi (2005). No âmbito de nossa pesquisa, levamos em consideração o político, procurando analisar como a rede eletrônica inscreve outra maneira de materializar os efeitos de luta, denúncia e reivindicação, dando voz a sujeitos aos quais foi negada a palavra; ou seja, nós concebemos a materialidade virtual como palco de disputas, um espaço político de dizer, no interior da luta de classes.

Observamos que, tal qual a Internet, o discurso é um espaço tenso, entre a língua e a história (FERREIRA, 2003), que está sujeito a transgressões e deslocamentos, afastando-se de concepções que o associam ao discurso empírico enunciado por um indivíduo, à noção de fala, do esquema tradicional da comunicação, em que alguém fala, sobre algo e em algum código, para um receptor que deve decodificar a mensagem; do mesmo modo, também não diz respeito ao texto no qual está encapsulado um conteúdo fixo, mas a "um verdadeiro nó, lugar teórico onde se intrincam questões sobre a língua, a história, o sujeito" (MALDIDIER, 2003, p. 15). Por essa perspectiva, o discurso é concebido como linguagem em interação, a mediação entre o homem e a realidade natural e social, sujeita a tensões e conflitos, visto que, como adiantamos, enunciar é uma prática política, ou seja,

InCID: R. Ci. Inf. e Doc., Ribeirão Preto, v. 1, n.1, p. 56-76, 2010. 
tomar a palavra é um ato social com todas as suas implicações: conflitos, reconhecimentos, relações de poder, constituição de identidade etc. [...] pois todo falante ocupa um lugar na sociedade, e isso faz parte da significação. (ORLANDI, 2000, p. 17).

É preciso reconhecer que essas relações de força de que falamos são materializadas na ordem da língua pelo viés da ideologia, levando-nos a apontar que "todo processo discursivo se inscreve numa relação ideológica de classes" (PÊCHEUX, 1997, p. 92), ou seja, é a ideologia que estabelece a constituição dos sentidos, que não estão colados às palavras, não são estabelecidos a priori, visto que estão sempre em movimento. Rompe-se, assim, com a ilusão da literalidade, da transparência do sentido, pois este sempre pode tornar-se outro, afetado pelas condições sócio-históricas e as circunstâncias da enunciação (a exterioridade constitutiva do discurso), além do tenso jogo das relações ideológicas de poder entre os sujeitos. Tais relações se materializam por meio das formações ideológicas, pois, de acordo com Pêcheux (1996, p. 145),

a instância ideológica, em sua materialidade concreta, existe sob a forma de 'formações ideológicas' (referidas aos Aparelhos Ideológicos de Estado), que tem um caráter regional e envolvem posições de classes.

Por sua vez, essas formações ideológicas são representadas, no discurso, pelas formações discursivas, nas quais o sentido se constitui. Sendo assim, na formulação pecheutiana, a noção de formação discursiva diz respeito a:

aquilo que, numa formação ideológica dada, isto é, a partir de uma posição dada numa conjuntura dada, determinada pelo estado da luta de classes, determina o que pode e deve ser dito [...] Isso equivale a dizer que as palavras, proposições etc., recebem seu sentido da formação discursiva na qual são produzidas. (PÊCHEUX, 1997, p. 160)

Compreendemos, assim, que a formação discursiva é a matriz dos sentidos, que, dependendo das posições assumidas pelos sujeitos, podem ser repetidos ou deslocados, no jogo da língua. Deste modo, as formações discursivas não são estanques, não constituem um bloco homogêneo, posto que não há apenas espaço para a reprodução dos sentidos, mas também para a sua transformação, para a ruptura e a possibilidade do novo, de outros lugares para o sujeito enunciar e produzir seu discurso. E é justamente através da ideologia e da filiação a uma formação discursiva, que os indivíduos são interpelados em sujeito, conforme é explicado por Pêcheux (1997, p. 161): “os 
indivíduos são 'interpelados' em sujeitos-falantes (em sujeitos de seu discurso) pelas formações discursivas que representam 'na linguagem' as formações ideológicas que lhes são correspondentes". Por conseguinte, temos que é o complexo das formações ideológicas que "fornece 'a cada sujeito' sua 'realidade' enquanto sistema de evidências e de significações percebidas-aceitas-experimentadas". (PÊCHEUX, 1997, p. 162).

Pelo mecanismo ideológico do assujeitamento, o sujeito é levado a ocupar seu lugar, a identificar-se com uma formação discursiva. Entretanto, o sujeito se esquece de que é assujeitado, pensando controlar o que diz. Ignorando a opacidade, a falta e o inconsciente que lhe constituem, o sujeito acredita ser a origem dos sentidos, que as palavras brotam nele; essa ilusão, necessária para que o sujeito possa enunciar, foi chamada, por Pêcheux (1997), de esquecimento número um. Alinhado a este, temos o esquecimento número dois, que é da ordem da enunciação e leva o sujeito a confiar na existência de uma relação termo a termo entre o seu pensamento e a sua palavra, pela qual se apagam outras formas de dizer. Posto isto, observamos que, através desses esquecimentos, alguns sentidos são vistos como naturais pelos sujeitos, como os únicos possíveis de serem enunciados, enquanto outros são apagados; contudo, mesmo estando legitimados, esses sentidos podem, como já foi dito, ser fraturados e mover, por meio das tensões que envolvem as formações ideológicas, a história e as relações de poder. $\mathrm{O}$ que nos leva a afirmar, assim como Maldidier (2003), que a ideologia, da mesma forma que a língua, não é um sistema hermético, mas esburacado, cheio de furos. Admite-se então que o assujeitamento não é radical, ou seja, que ele comporta falhas, abrindo um espaço para o sujeito resistir, já que "não há identificação plenamente bem-sucedida". (PÊCHEUX, 2002, p. 56).

Inferimos que, do mesmo modo que o discurso e a ideologia, o sujeito é também passível de falhas e equívocos, marcado pelos furos em seus dizeres. Por essa ótica, o sujeito é entendido por nós não como indivíduo totalmente consciente, o ser empírico, sujeito cartesiano dono de seu dizer, que pode ser quantificado e classificado, mas como sujeito do discurso, que segundo Orlandi (2003b, p. 20) "funciona pelo inconsciente e pela ideologia." É concebido, assim, como um efeito de linguagem, podendo ocupar diferentes posições, a partir das quais ele constrói sentidos, afetado pelas condições sócio-históricas e ideológicas. Essas posições, que podem ser assumidas pelo sujeito ao enunciarem, são determinadas também pelas formações imaginárias, da ordem do inconsciente; por meio delas é que as imagens dos sujeitos, resultado de projeções, InCID: R. Ci. Inf. e Doc., Ribeirão Preto, v. 1, n.1, p. 56-76, 2010. 
funcionam na linguagem; são elas que permitem a passagem de uma situação empírica (lugar do sujeito) para uma posição do sujeito no discurso. Tais projeções, afetadas pela exterioridade, constituem um jogo que regula a troca de palavras, produzindo, também, imagens do objeto discursivo.

Inferimos, em consonância com a teoria discursiva que a memória discursiva (ou interdiscurso) sustenta produção dos sentidos, as posições assumidas pelo sujeito para enunciar, visto que ela sustenta cada tomada da palavra, fundamentando o dizer. Compreendida por Pêcheux (1997, p. 162) como o "'todo complexo com dominante' das formações discursivas", a memória corresponde ao "saber discursivo que torna possível todo o dizer e que retorna sob a forma do pré-construído, o já-dito que está na base do dizível" (ORLANDI, 2003b, p. 31), às zonas do já-lá que são recortadas pelos sujeitos para poderem enunciar, já que, como dissemos, eles não são os donos dos seus dizeres. Ainda sobre o funcionamento do interdiscurso, é importante destacarmos que as relações discursivas tecidas entre a memória e a atualização, a repetição e o deslocamento, mostram-nos que ele não pode ser entendido de forma estática, como:

uma esfera plena, cujas bordas seriam transcendentais históricos e cujo conteúdo seria um sentido homogêneo, acumulado ao modo de um reservatório: é necessariamente um espaço móvel de divisões, de disjunções, de deslocamentos e de retomadas, de conflitos e de regularização. Um espaço de desdobramentos, réplicas, polêmicas e contra-discursos. (PÊCHEUX, 1999, p. 56).

Através desse caráter descentralizador, mobilizado pelo constante jogo de poder entre discursos e contra-discursos, assegura-se a possibilidade de que se produza o diferente, a partir do mesmo, de que possa emergir "o fato novo, as cifras, as primeiras declarações" (PÊCHEUX, 2002, p. 19), ou, ao contrário, que um já-dito retorne no discurso, preso à circularidade do sentido dominante com o qual não rompe; e são nesses jogos entre a paráfrase e a polissemia que, segundo Orlandi (2003b), os sujeitos se movimentam e (se)significam. Por isso, ao enunciarem, os sujeitos são afetados não apenas pela memória discursiva, o já-dito, mas também por outras vozes, por sentidos emprestados de outrem, ou seja, pela heterogeneidade discursiva. Esse atravessamento de vozes no discurso do sujeito pode ocorrer de forma mostrada, explícita, através do uso de citações, depoimentos, discursos direto e indireto, comentários, ironia, dentre outras "formas marcadas que atribuem ao outro um lugar linguisticamente descritível, claramente delimitado no discurso" (AUTHIER-REVUZ, 2004, p. 21). Além dessas InCID: R. Ci. Inf. e Doc., Ribeirão Preto, v. 1, n.1, p. 56-76, 2010. 
formas marcadas de heterogeneidade, que nos lembram que as palavras são habitadas por discursos, destacamos a heterogeneidade constitutiva, implícita, que corresponde ao constante retorno do interdiscurso, ao sempre-já-aí da interpelação ideológica (PÊCHEUX, 1997), que procuraremos flagrar no processo de constituição dos discursos sobre a biblioteca escolar, na rede eletrônica.

\section{Nas redes da Internet: discursos e sujeitos em movimento}

As palavras, se não o sabe, movem-se muito, mudam de um dia para o outro, são instáveis como sombras, sombras elas mesmas, que tanto estão como deixaram de estar, bolas de sabão. - José Saramago

Como analistas do discurso, consideramos que ele não corresponde à materialidade de palavras fixas, imutáveis, visto que compõe uma trama de sentidos sempre em (re)construção, que se mostra instável e provisória; como as sombras, que mudam de lugar e tamanho ao sabor da claridade, ou as bolas de sabão, que se movem refletindo múltiplos efeitos de cor, dependendo da maneira como a luz as atravessa, até desmancharem-se no ar. Deste modo, não é apenas a fluida materialidade virtual que é posta, pelos sujeitos-navegadores, em contínuo deslocamento, não são apenas os links e sites que, ao serem navegados, podem ser desativados ou modificados a cada segundo, mas também os discursos que neles se sustentam e podem ser atualizados ou esquecidos, conforme o modo como eles se trançam com a história, a memória e a ideologia, que afetam a produção e circulação dos sentidos na rede. Isso porque, por ter o movimento e a instabilidade como constitutivos, "todo enunciado é intrinsecamente suscetível de tornar-se outro, diferente de si mesmo, se deslocar discursivamente de seu sentido para derivar para um outro" (PÊCHEUX, 2002, p. 53), compondo uma série de pontos de deriva possíveis, que oferecem um lugar de interpretação, em meio à estrutura aberta, plural e descentralizada das redes eletrônicas, onde "a única constância parece ser a da inevitabilidade das ressignificações, umas sobre as outras, ou seja, o inconstante". (MITTMANN, 2008, p. 115)

Essa inconstância faz com que o sujeito-navegador percorra "os nós da rede de uma forma totalmente imprevisível, muitas vezes até para ele próprio” (LEÃO, 2005, p. 57), não havendo, assim, caminhos pré-definidos a serem seguidos, na medida em que, segundo Castells (2003, p. 171), “cada nó está conectado a todos os outros através de 
uma miríade de rotas possíveis". Por conseguinte, o espaço ciber se reestrutura e reconfigura a cada passo, não sendo possível termos uma visão aérea deste ambiente movediço, que se abre quando o sujeito-navegador emerge na rede e se movimenta de maneira indefinida, "equilibrando-se entre a desorientação mais turva e a iluminação mais cintilante". (SANTAELLA, 2004, p. 103). Ao navegar por entre links e arquivos sem linearidade lógica, "o sujeito passa de um texto jornalístico a uma receita de bolo, de uma rede de amigos a outra de serviços, construindo-se diversas tramas discursivas que se entrecruzam em um todo desconexo e fragmentado" (FERRAREZI; ROMÃO, 2007, p. 260). Delineia-se, assim, uma tessitura textual que desenha uma teia de associações, caminhos limitados pelo trajeto percorrido pelo sujeito em seus movimentos de leitura, construção e interpretação de sentidos pelo labirinto virtual, os quais deixam suas marcas ao longo do percurso que, para Ramal (2002, p. 84), é "tecido de maneira original e única pelo leitor cibernético".

A respeito das maneiras de ler na materialidade virtual, é importante ressaltarmos primeiro que toda leitura é um gesto de atribuição de sentidos, que depende da posição do sujeito e do modo como a ideologia o interpela em sujeito de suas leituras; tal concepção está em consonância com a teoria da Análise do Discurso, pela qual se desconstroem os sentidos de uma leitura única, certa ou natural, que não leva em conta as relações com a exterioridade e o interdiscurso - restrições estas que não cabem em um espaço desterritorializado, que é atravessado freneticamente por várias vozes e discursos, percorrido por um sujeito-leitor em estado de prontidão, que se conecta "entre nós e nexos, num roteiro multilinear, multissequencial e labiríntico que ele próprio ajudou a construir ao interagir com os nós entre palavras, imagens, documentação, músicas, vídeo etc." (SANTAELLA, 2004, p. 33).

Inferimos que a virtualidade da rede parece escancarar a multiplicidade que constitui todo discurso, instalando novas formas de ler e produzir sentidos, de relacionar-se com discursos outros, nos quais se pode intervir, de forma mais ampla, no próprio conteúdo. Desse modo, segundo Chartier (1999, p. 92),

levado por uma nova técnica e um novo suporte, o texto pode se oferecer às manipulações do leitor, cujas intervenções não serão reduzidas, como no caso do livro impresso, a insinuar uma escritura manuscrita nos espaços brancos deixados pela impressão tipográfica.

InCID: R. Ci. Inf. e Doc., Ribeirão Preto, v. 1, n.1, p. 56-76, 2010. 
Essas possibilidades de o sujeito-leitor fazer intervenções nos discursos, reordená-los e deslocá-los implicam, muitas vezes, um movimento de recorte, supressões e recolocações que os deslocam de seus contextos e conferem à leitura um caráter descontínuo, pois o sujeito:

busca, a partir de palavras-chave ou rubricas temáticas, o fragmento textual do qual quer apodera-se (um artigo em um periódico, um capítulo em um livro, uma informação em um website), sem que necessariamente sejam percebidas a identidade e a coerência da totalidade textual que contém esse elemento. Num certo sentido, no mundo digital todas as entidades textuais são como bancos de dados que procuram fragmentos cuja leitura absolutamente não supõe a compreensão ou percepção das obras em sua identidade singular. Assim, quanto à ordem dos discursos, o mundo eletrônico provoca uma tríplice ruptura: propõe uma nova técnica de difusão da escrita, incita uma nova relação com os textos, impõe-lhes uma nova forma de inscrição (CHARTIER, 2002, p. 23-4).

Sendo assim, essa nova forma de inscrição dos discursos no ciberespaço, aos moldes de um patchwork de sentidos múltiplos, permite que o sujeito os leia a partir de qualquer ponto e direção,

do início para o final e/ou do final para o início, vasculhado a partir de outro rastreamento que não aquele que levava em conta o início, meio e final com a leitura iniciada sempre pelo lado esquerdo e com o dedo deslizando em direção à direita e à linha debaixo. (ROMÃO, 2005, p. 4).

Por fim, observamos que essa fragmentação dos discursos e dos gestos de leitura faz, também, com que os sujeitos possam escapar, migrar para outras regiões de sentido, desviar-se das rotas que começaram a percorrer, visto que:

A navegação on-line permite que um trajeto seja interrompido e modificado de direção a qualquer clique, ampliando as chances de o leitor escapar por meio de outras páginas eletrônicas e por entre as frestas da imensidão desta teia de conexões. Do interior de um texto, há possibilidade de deslocamento, errância em diversas direções, pois as janelas do ciberespaço se abrem em uma fundura de navegação polidimensional. (ROMÃ̃, 2004b, p. 72-3)

Posto isto, associamos o sujeito-navegador a um leitor ativo, um construtor de labirintos, "que está a todo momento estabelecendo relações próprias entre diversos caminhos" (LEÃO, 2005, p. 16), múltiplas possibilidades de atualização de sentidos, que configuram uma nova forma de ler, a qual pensamos ser mais aberta à polissemia, a um vir-a-ser constante; visto que a Internet é um espaço que se desdobra e que oferece “oportunidades de leitura em diferentes direções [...] um espaço de informação e 
interação constituído por uma complexa malha de significados, aos quais o próprio sujeito atribui ordem e entendimento, não sendo apenas espectador". (SILVA, 2006, p. 73).

Em meio às diversas possibilidades de interpretação e (re)construção dos discursos, marcamos que a cópia, desmembramento, recomposição ou deslocamentos dos textos digitais sinalizam a tênue fronteira existente entre as posições de sujeitoleitor e autor, o público e o privado, sentidos constituídos por mim e pelo outro, destacando a importância da heterogeneidade dos discursos e do sujeito, o qual "se define agora como sendo a relação entre o 'eu’ e o ‘outro'. O sujeito é constitutivamente heterogêneo, da mesma forma que o discurso o é”. (MUSSALIM, 2001, p. 134). Assim sendo, no fluxo movediço que condiciona o dizer na rede, circulam vozes heterogêneas e justapostas de forma desarranjada, sujeitos errantes que se deslocam entre palavras, imagens e arquivos alheios, mantendo-se sempre em um movimento de avanço ou retorno, no

entre-meios de páginas, links e ícones que o endereçam a outros sítios, a tantas teias intertextuais [...] múltiplas entradas para pisar na voz do outro, diversas janelas para abrir arquivos que, como eu disse anteriormente, já foram previamente escolhidos. (ROMÃ̃, 2006, p. 309).

Observamos que esta relação com discursos outros pode envolver tensões e conflitos, que indiciam as relações de força pelas quais se tenta silenciar certas vozes, apagando determinadas regiões de sentido das quais o sujeito se apropria como se fossem suas, ou com as quais ele não se alinha. Essas tentativas de apagar a heterogeneidade são da ordem do inconsciente, do ideológico, pois, assim como os sujeitos não são donos dos seus dizeres e nem os controlam, eles têm seus movimentos de navegação na rede afetados pelas formações discursivas que os dominam e manifestam as formações ideológicas que os levam a legitimar (ou não) alguns discursos, dentre tantos com os quais se relacionam na virtualidade da rede, que "possibilita essa con-fusão de vozes, posições e representações nas redes de filiação" (ROMÃO, 2008, p. 96). É importante observarmos que as formações discursivas de que falamos, e dizem respeito à matriz dos sentidos que regula o que pode ou não ser dito nas redes da Internet, são definidas a partir do interdiscurso que, segundo Orlandi (2003b, p. 31), "disponibiliza dizeres que afetam o modo como o sujeito significa em uma situação discursiva dada". Assim sendo:

InCID: R. Ci. Inf. e Doc., Ribeirão Preto, v. 1, n.1, p. 56-76, 2010. 
No entre-meio dos links, a ordem da língua e a ordem da história reclamam o tempo todo que a linguagem seja significada a partir do que não está na tela, mas do que a memória histórica e a memória do dizer cavaram em outros locais, em outros atos de dizer e em outras inscrições sociais dos significantes. (ROMÃO, 2005, p. 6-7)

Portanto, para o sujeito-navegador da rede, os links, que se remetem uns aos outros e colam-se mutuamente o tempo todo em uma teia de nós e conexões, só fazem e constroem sentidos se ele tiver acesso à memória e ao arquivo em movimento na rede, posto que o sujeito se inscreve, segundo Romão (2006, p. 307), em "locais que já foram autorizados, previamente lidos e acomodados" por outros sujeitos, movimentando-se na rede do já-dado e traçado, entre nós que já foram atados por outrem, deslocando-se:

permanentemente sem parada, inscrevendo (-se em) ditos nos meandros de dizeres que se apoiam em outros ditos, consumindo (-se) palavras sob as cifras de outras palavras, brincando de enunciar a si mesmo a partir das palavras dos outros, enfim, percorrendo dizeres já inscritos e já propagados e formulando outros. (FERRAREZI; ROMÃO, 2007, p. 259)

Em meio à heterogeneidade, o sujeito percorre, em seus movimentos de navegação, leitura e descobrimento da rede, zonas de memória ressignificadas por outros sujeitos, com as quais ele se relaciona e pode, a partir daí, instalar uma nova discursividade, o diferente, ao constituir uma outra forma dos sentidos funcionarem, que é sustentada pelas potencialidades dadas pelo ciberespaço, pela "mutação gerada pela tecnologia digital e consequentemente pela materialidade assumida por essa discursividade" (DIAS, 2004, p. 19). Dessa maneira, podemos dizer que novas formas de inscrição do sujeito e dos sentidos na história podem ser constituídas a partir da retomada da memória, em um movimento pelo qual, segundo Mittmann (2008, p. 11), "as expressões e os modos de dizer antigos passam a adquirir sentidos particulares, através de acontecimentos discursivos, numa reinterpretação que se faz necessária". Temos, assim, um jogo entre a estrutura e o acontecimento (PÊCHEUX, 2002), que instala, na ordem da língua, o movimento da retomada de palavras já existentes, como se elas brotassem no sujeito, de sentidos que já circularam em outros contextos e do vira-ser de outros, que se entrelaçam aos primeiros rompendo com o estabilizado, em uma tensão que constitui o próprio discurso, o qual significa "sempre de muitas e variadas maneiras. Sempre as mesmas mas, ao mesmo tempo, sempre outras". (ORLANDI, 2003b, p. 36)

InCID: R. Ci. Inf. e Doc., Ribeirão Preto, v. 1, n.1, p. 56-76, 2010. 
Observamos que, dependendo de sua relação com a memória e a ideologia, o sujeito-navegador pode ocupar determinadas posições no discurso, que não são únicas, mas também não podem ser qualquer uma, o que indicia os limites para o ler, surfar e enunciar no suporte eletrônico. Apesar de não podermos desconsiderar as restrições que impedem o alcance do todo, sugerimos que a Internet abre espaço para a circulação de sentidos mais plurais e o sujeito-navegador, na ânsia de desbravar outros mares, diante da amplidão do oceano digital, experimenta a Internet de muitas formas: representando suas fantasias e experimentando "alter-egos de maneira que muitos de nós não nos arriscaríamos a fazer no mundo físico" (WERTHEIM, 2001, p. 175), valendo-se, frequentemente, do apagamento dos nomes (substituídos pelos nicknames - apelido), imagens (agora, avatares) ou marcadores sociais do espaço físico, como o país; ocupando lugares que, muitas vezes, são impossíveis no mundo real, dos quais ele pode enunciar de diferentes formas, de acordo com o jogo entre formações imaginárias e o modo como é interpelado pela ideologia e acessa o interdiscurso; recortando e ressignificando certas regiões de sentido, que podem migrar para outras em um segundo; compondo seus ditos e interditos trançando-os a vozes e discursos de outros sujeitos dispersos na rede.

Inferimos também que, além da possibilidade de emergência da polissemia e da ocupação de outras posições-sujeito, a rede abre espaço para a inclusão e enunciação dos sujeitos aos quais foi negada a palavra, em outros contextos; instala-se assim um furo, uma rachadura no movimento de silenciamento, por meio da qual o sujeito resiste,

se rebela contra o que é ou está naturalizado, o que inquieta a ordem e desconstrói o silêncio. Na gangorra da memória e do silêncio, o sujeito resiste e insiste em materializar sua presença, instalam (-se) dizeres que dão corpo e link aos sentidos de sua exclusão. (ROMÃO, 2004a, p. 44)

Assim, a Web faz com que os sujeitos-internautas tenham a oportunidade de passear por diferentes formações discursivas, observar as várias vozes que as constituem, a porosidade destas formações, que se interpenetram, reverberando os sentidos que não querem/podem calar.

Entretanto, vale ressaltarmos que, para que os sujeitos sejam realmente incluídos no ciberespaço, é preciso mais do que o acesso à Internet e outras ferramentas de comunicação e informação, sendo fundamental que eles se relacionem com os sentidos 
postos em circulação nas redes eletrônicas, que participem ativamente dos jogos de (re)construção e interpretação dos discursos que elas sustentam. Assim, ainda que a rede abrigue sentidos plurais, isto não é suficiente para uma democratização dos discursos, visto que "não basta as ideias estarem lá depositadas, é preciso que elas circulem, que elas tomem corpo, que elas reverberem, isto é, que elas entrem na ordem do discurso e não fiquem apenas ‘à deriva na superfície das águas'”(MELO, 2005, p. 137).

\section{A biblioteca escolar na rede eletrônica: movimentos discursivos de interpretação}

As palavras são apenas pedras postas a atravessar a corrente de um rio, se estão ali é para que possamos chegar à outra margem, a outra margem é que importa. A não ser que esses tais rios não tenham duas margens, mas muitas, que cada pessoa que lê seja, ela, a sua própria margem, e que seja sua, e apenas sua, a margem a que terá de chegar. - José Saramago

Ao nos indagarmos se a rede eletrônica abriria espaço para a emergência de outros sentidos sobre a biblioteca escolar, lançamos a hipótese de que o ciberespaço heterogêneo e interativo faz falar também o plural, permite os furos nas regiões de sentido estabilizadas pelo retorno da memória, suscitando outras maneiras de enunciar sobre essa instituição, de interpretá-la, procurando chegar a outras margens de sentido. Em busca de respostas, percorremos algumas rotas de navegação que nos levaram a investigar, primeiramente, os pressupostos teóricos da Análise do Discurso, que considera a língua opaca, faltante, passível de falhas e deslocamentos. A partir desse lugar teórico, buscamos compreender melhor como os discursos são materializados na instável teia digital, como se dão os movimentos de sujeitos e a deriva dos sentidos, inscrevendo outros gestos de leitura e interpretação que ultrapassem as concepções técnicas e universalistas circulantes nos discursos sobre esse ciberespaço.

Imbuídas desse propósito, nós observamos que os movimentos heterogêneos de sujeitos-navegadores, dos quais falamos anteriormente, são ainda mais dinâmicos nas listas de discussão. Assim sendo, flagramos, nos recortes que mostraremos a seguir, publicados na lista de discussão Bibamigos (AJUDA... 2009), entre os dias 23 e 24 de dezembro de 2009, efeitos de sentidos que se entremeiam em uma rede de significações mais plurais sobre a biblioteca escolar e que foram enunciados a partir de uma indagação, que gerou duas respostas. Conheçamos o primeiro nó dessa rede: 
Amigos, em março/2010 iniciarei o trabalho em uma biblioteca escolar e já comecei a estudar mais sobre tema, as particularidades dessa instituição e questões conceituais, pois a prática de catalogação, classificação, eu já tenho. Por isso, gostaria que vocês me falassem um pouco sobre as bibliotecas escolares: o que vocês pensam sobre ela? Vocês conhecem boas bibliotecas escolares? E o bibliotecário escolar, existe?

Destacamos que, através das indagações feitas, o sujeito instala um efeito de dúvida em relação à existência de boas bibliotecas escolares e do bibliotecário escolar, posto que é necessário que alguém a confirme, ateste sua veracidade, desnaturalizando, assim, os dizeres inscritos em uma formação discursiva que insere a biblioteca em uma esfera idealizada, onde todas as unidades de informação escolares seriam adequadas e implicariam a presença do bibliotecário. Tais formulações são indícios, também, de um interesse pela biblioteca, por conhecê-la, estudá-la, investigar seu conceito, indo além das questões técnicas. Esse posicionamento suscitou a emergência de outros, que também encontraram um espaço, nesta lista, para enunciar de uma maneira diferente, mais plural, sobre a biblioteca escolar. Vejamos:

Vou te dar a minha impressão de criança que frequentou biblioteca escolar
quando este termo não era ainda disseminado. Meu interesse pelos livros
começou justamente porque uma professora, ainda no Jardim de Infância,
expôs alguns livros muito atrativos, coloridos, e de tamanhos variados, em
local de fácil acesso e sem burocracia para nós alunos, ainda aprendendo a
ler. Esta experiência modificou a minha vida a ponto de eu e meus amigos ao
longo da vida escolar procurarmos sempre pela biblioteca da escola, uma
salinha um pouco suja e desarrumada, isto se deu até entrarmos no ensino
médio. Traduzindo, como usuária apaixonada, identifiquei sempre primeiro
boa vontade, atenção e pouca burocracia. Por mais que a biblioteca seja farta
de acervo, tenha tecnologia disponível, o que conta é o ser humano "por trás
do balcão". Este é o fator que vai fazer o usuário voltar ou não.

Através dos sentidos que discursivizam seus primeiros contatos com os livros, sua impressão dos mesmos, o sujeito atribui importância à biblioteca e às ações dinamizadoras das obras, que as apresentem ao sujeito-leitor de forma criativa e sem restrições, levando a práticas interessantes e transformadoras. A partir dessa perspectiva mais ampla e aberta a outras possibilidades, acredita-se poder minimizar os problemas existentes nas bibliotecas, que funcionam, muitas vezes, como uma salinha um pouco suja e desarrumada; sendo assim, confere-se valor ao profissional que atua na biblioteca escolar, um importante papel que pode significar a sua estagnação ou dinamicidade. Concordamos com a importância atribuída a esse profissional, mas ressaltamos que é necessária, também, uma ação conjunta, que engloba a atuação política, docente, 
estudantil e, também, familiar e social. Comumente as ações de sucesso em bibliotecas não dependem necessariamente de condições ideais, mas se houver a disponibilidade de maiores recursos, eles potencializarão os resultados alcançados. Observamos ainda que, muitas vezes, a falta de alguns elementos pode impedir que as ações sejam realizadas; assim sendo, não se pode deixar todas as ações a serem realizadas sob a responsabilidade do profissional que trabalha na biblioteca escolar. Em uma segunda resposta enviada à pergunta inicial, percebemos um embate entre o discurso dominante e aqueles que o furam, pelo qual se contrapõem os sentidos que apontam para os problemas das bibliotecas escolares e para práticas mais polissêmicas que as valorizam, como vemos a seguir:

Eu adoro o universo da biblioteca escolar. Se um dia puder me custear, até trabalho em uma, porque pagam muito mal (cerca de 1000 a 1300 contos... por oito horas de trampo... vich, só pra quem pode ter um salário destes depois de estudar 5 anos.

Podemos inferir que baixos salários estariam em consonância com os sentidos de desvalorização da biblioteca, e, nesse discurso, marcam a impossibilidade de atuar nela, apesar do interesse demonstrado. Outro recorte em que se instala esse litígio entre formações discursivas está transcrito a seguir:

Bom, se eu pudesse resumir, diria que a biblioteca escolar é a casa da invenção, como diz o Título do prof. Milanesi. Mas não pode desanimar, porque a verdade é que os alunos não gostam de ler, ao menos a maioria. Com minhas invenções, já vi muitos milagres acontecerem, tipo o aluno mais bagunceiro da escola ler algo que nunca leria antes... "Como educar seus pais" ou sobre a vida do rei Arthur.

A biblioteca é discursivizada por esse sujeito como um lugar dinâmico, que precisa ser (re)inventado para que seja possível superar os problemas, como o da falta de gosto pela leitura. Através da persistência de práticas mais polissêmicas, alguns "milagres" podem ocorrer, suscitando a emergência de sentidos mais coloridos acerca da biblioteca e de suas atividades, aproximando-as dos sujeitos leitores, que precisam ser seduzidos, "captados" na teia envolvente da biblioteca:

Eu inventava muito. Ficava, em vez de polindo o acervo para ninguém, engenhando formas e formas de captar seguidores das boas letras. Era como planejar de que lado iria armar a teia de aranha para pegar minhas 'vítimas'. Colocava recados importantes pregados com desenhos engraçados no monitor dos computadores, eu sabia que ali eles iriam ler... Até poesia liam assim. Espalhava pilhas de livros (os de capa dura e, portanto, mais resistentes) pelo pátio para que eles tropeçassem na hora do recreio (assim InCID: R. Ci. Inf. e Doc., Ribeirão Preto, v. 1, n.1, p. 56-76, 2010. 
perceberiam que existia vida por trás do balcão da biblioteca...). Colava poesias no piso, perto do banco onde eles sentavam e cobria com contact (sabe como é, sentou ali, nada pra fazer... 'O que é isto aqui no chão?'), mantinha minhas máscaras de gesso à mão para que eles brincassem com elas de teatro, usava uma máquina velha de slides para contar histórias ou lendas clássicas e tem até filme de dança do caranguejo dentro da biblioteca... Indicava livros com títulos interessantes, como 'Tem uma lagartixa dentro do meu computador' ou 'Como educar seus pais'.

Acho que sou tão fascinado pela biblioteca escolar que poderia escrever um livro que chamaria 'As peripécias de um bibliotecário maluco para captar leitores ariscos em uma biblioteca escolar'. Sempre odiei o 'psiu!', eles podiam trocar ideias e sempre o faziam dentro da biblioteca. A moderação era um pedido e não uma ordem. Em vez de 'proibido conversar' ou 'silêncio', a placa era 'permitido falar baixo'.

Assim, através de uma variedade de atividades criativas e inusitadas, que visam à aproximação com o sujeitos-leitores, estes poderiam deixar-se enredar na biblioteca, instigados pela curiosa maneira de mediar as obras e os recursos disponíveis na mesma. Essas ações, implementadas com prazer e fascínio, seriam acompanhadas de uma prática que permite a circulação do discurso polêmico e lúdico na biblioteca, que vão de encontro à sua burocratização e cerceamento. Assim, apesar das dificuldades encontradas, poderiam emergir sentidos que delineiam um jogo de formações imaginárias bem diferente para a biblioteca, próxima daquela considerada ideal. Os problemas que envolvem a biblioteca são discursivizados de uma maneira diferente, instalando outros efeitos que não os de repetição, conforme veremos a seguir, nos recortes do blog Diário de uma biblioteca escolar (DESESPERO... 2008), publicados no dia 6 de março de 2008. Neles, o sujeito coloca em discurso, de maneira particular e informal, sua relação com a biblioteca e com seu fazer bibliotecário, apontando as dificuldades enfrentadas quando se tenta cumprir sozinho as várias funções em uma biblioteca escolar, do cadastramento dos livros à mediação do acervo.

\footnotetext{
Cara, tem dia que dá um desespero total neste lugar. Imagine, 10 mil livros para cadastrar e gente te pedindo livros didáticos que você não sabe se tem, assuntos temáticos que exigiriam um resumo dos livros... você fica louco se levar muito a sério. O que eu faço? Respiro fundo e vou. Sento com meus usuários alunos para ver do que eles precisam e como vão indo nas matérias, fico atento aos professores e pesquiso coisas antes até que me peçam, mexo com a cabeça dos alunos da forma que consigo, para levarem a sério os estudos e terem também a leitura do prazer.
}

Assim, diante das dificuldades encontradas e o desespero que elas causam, o sujeito precisa priorizar algumas atividades, em detrimentos de outras. No discurso em 
questão, transgride-se uma prática recorrente, optando-se por enfocar a relação e o atendimento aos usuários alunos, o estímulo à leitura e à pesquisa, delineando novas práticas sociais e discursivas acerca da biblioteca escolar, utilizando, para tanto, novos meios de produção de sentidos, visando a aproximar-se dos sujeitos, instigá-los a participarem, a se inserirem nela, para produzirem outros gestos de leitura e escrita. Nos recortes do blog Diário de uma biblioteca escolar (MINHA... 2008), publicados no dia 10 de março de 2008, encontramos também sentidos mais polissêmicos em relação às práticas realizadas na biblioteca escolar, discursivizados nas seguintes sequências:

devo tomar um café para prosseguir com a brincadeira feliz de estar nessa biblioteca, atender almas sedentas daquilo que nem sabe que estão, dar comida invisível a mentes voláteis. [...] não vejo a hora de voltar para os meus amigos livros e para meus clientes, os usuários. Diversão sem preço. Olho pela porta para ver se não caiu nenhum inseto em minha teia. Ainda não. Hoje de manhã consegui pegar uma mosquinha na teia.

O trabalho em uma biblioteca é discursivizado, aqui, não como desinteressante ou monótono, mas como uma brincadeira feliz, uma diversão sem preço. A partir dessa ótica aparentemente despretensiosa, abre-se espaço para a emergência de outras posições-sujeito, de outras funções para as bibliotecas, vistas nesse discurso não apenas como auxiliares à educação, mas como fundamentais, já que concedem o alimento que sustenta o aluno, em seus percursos no âmbito escolar e fora dela. A partir dessa concepção, os sentidos que legitimam o silêncio e a ordem rígida em uma biblioteca seriam desconstruídos.

Eles iam sentando, aos pouco. Sempre perguntando muito, mexendo em tudo... Santa bagunça, eu adoro isto! Prefiro do que o gelo de nada fazer e nada ter para fazer... Adoro arrumar a bagunça quando eles saem. São uns furacõezinhos maravilhosos que me enchem a alma de esperança nos leitores do futuro. Perguntadeiros, conversadeiros, espertos pedacinhos de gente. Peguei um livro que não fosse muito extenso e comecei a contar uma história de uma princesa, a princesa 'Mãe d'água'. [...] Eu quero mais é que eles venham e derrubem tudo. Construo de novo com o maior prazer.

A biblioteca escolar é aqui discursivizada como um lugar vívido, movimentado, que permitiria a emergência de sujeitos-leitores, instalando um lampejo de esperança, em meio aos sentidos que evocam o desprestígio conferido à leitura, que é mostrado no excerto a seguir: "Ah que inveja os livros de romance sentem dos livros didáticos. Se pudessem acompanhar aquelas crianças nas aulas, ficariam quentinhos ali, guardados nos armários esperando a hora de serem folheados e lidos”. A partir desses dizeres, o 
sujeito denuncia que as atividades pedagógicas são calcadas no livro didático, abrindose pouco espaço para outras leituras, acarretando, assim, a sub-utilização da biblioteca, vista aqui como um almoxarifado, resumida a um armário para alocar os livros didáticos utilizados em sala de aula.

Para que tais práticas restritas possam ser desestabilizadas, é importante que a biblioteca assuma uma postura mais maleável, flexível, que não se preocupe só em conservar, mas fazer circular obras e sujeitos perguntadeiros, conversadeiros, espertos furacõezinhos maravilhosos, desestabilizando, bagunçando, derrubando tudo, para poder organizar e instaurar a santa bagunça novamente, sucessivamente. Assim, inferimos que o trabalho em uma biblioteca escolar nunca está concluído, pois uma biblioteca viva implica movimento, quebra de ordens, ruptura de previsibilidades, o que pode permitir a emergência de outros sentidos e gestos de leitura e significação com o maior prazer. Por fim, consideramos que a Internet é um lugar discursivo de sentidos mais plurais, dados pelos confrontos de diferentes formações discursivas que se interpenetram, em que a voz de sujeitos inscrevem-se em movimentos constantes de justaposição em uma espiral com sentidos a perder de vista, propiciada pela volatilidade da própria rede e pela maleabilidade do discurso.

\section{Referências}

AJUDA-biblioteca escolar. 2009. Disponível em: <http://br.groups.yahoo.com/group/ bibamigos/message/27074>. Acesso em: 26 dez. 2009.

AUTHIER-REVUZ, Jacqueline. Heterogeneidade mostrada e heterogeneidade constitutiva: elementos para uma abordagem do outro no discurso. In: Entre a transparência e a opacidade: um estudo enunciativo do sentido. Porto Alegre: EDPUCRS, 2004. p. 11-80.

CASTELLS, Manuel. A galáxia da Internet: reflexões sobre a Internet, os negócios e a sociedade. Rio de Janeiro: Ed. Jorge Zahar, 2003.

CHARTIER, Roger. A ordem dos livros: leitores, autores e bibliotecas na Europa entre os séculos XIV e XVIII. 2.ed. Brasília: Ed. UnB, 1999.

Os desafios da escrita. Tradução de Fúlvia M. L. Moretto. São Paulo: Ed. UNESP, 2002. 
DESESPERO pairando pelos ares fungóginos. 2008. Acesso em:

$<$ http://diriodeumabibliotecaescolar.blogspot.com/2008/03/desespero-pairando-pelosares-fongginos.html >. Acesso em: 13 set. 2009.

DIAS, Cristiane Pereira. A discursividade da rede (de sentidos): a sala de bate-papo HIV. 2004. 176 f. Tese (Doutorado) - Instituto de Estudos da Linguagem, Universidade Estadual de Campinas, Campinas, 2004.

FERRAREZI, Ludmila; ROMÃO, Lucília Maria Sousa. Morte "'anunciada": sentidos de memória e heterogeneidade no discurso jornalístico. Revista Signótica, Goiânia, v. 19, n. 2, p. 255-76, jul./dez. 2007. Disponível em:

<http://www.revistas.ufg.br/index.php/sig/article/viewFile/7469/5292>.

FERREIRA, Maria Cristina Leandro. Da ambiguidade ao equívoco: a resistência da língua nos limites da sintaxe e do discurso. Porto Alegre: Ed. UFRGS, 2000.

Nas trilhas do discurso: a propósito de leitura, sentido e interpretação. In:

ORLANDI, Eni. (Org.). A leitura e os leitores. 2 ed. Campinas: Pontes, 2003.

LEÃO, Lúcia. O labirinto da hipermídia: arquitetura e navegação no ciberespaço. 3.ed. São Paulo: Iluminuras, 2005.

MALDIDIER, Denise. A inquietação do discurso: (re)ler Michel Pêcheux hoje. Tradução de Eni P. Orlandi. Campinas: Pontes, 2003.

MELO, Cristina Teixeira Vieira de. A análise do discurso em contraponto à noção de acessibilidade ilimitada da Internet. In: MARCUSCHI, Luiz Antônio; XAVIER, Antônio Carlos (Orgs.). Hipertexto e gêneros digitais. 2.ed. Rio de Janeiro: Lucerna, 2005.

MINHA primeira "Hora do Conto". 2008. Disponível em: $<$ http://diriodeumabibliotecaescolar.blogspot.com/2008/03/minha-primeira-hora-doconto.html>. Acesso em: 24 nov. 2009.

MITTMANN, Solange. Redes e ressignificações no ciberespaço. In: ROMÃO, Lucília Maria Sousa; GASPAR, Nádea Regina. (Orgs). Discurso midiático: sentidos de memória e arquivo. São Carlos: Pedro \& João Ed., 2008, p. 113- 130.

MUSSALIM, Fernanda. Análise do Discurso. In: MUSSALIM, Fernanda; BENTES, Anna Christina (Orgs.). Introdução à Lingüística: Domínios e Fronteiras. São Paulo: Cortez, 2001, p. 101-142.

ORLANDI, Eni P. Discurso e leitura: as formas do discurso. 5.ed. São Paulo: Cortez, 2000 .

A Linguagem e seu funcionamento: as formas do discurso. 4. ed. Campinas: Pontes, 2003a.

$2003 b$.

Análise de discurso: princípios \& procedimentos. 5. ed. Campinas: Pontes, 
Michel Pêcheux e a análise do discurso. Estudos da Língua(gem), Vitória da

Conquista, n.1, p. 9-13, jun. 2005. Disponível em: <http://www.cpelin.org/

estudosdalinguagem/n1jun2005/artigos/orlandi.pdf>. Acesso em: 10 jan. 2010.

PÊCHEUX, Michel. O mecanismo do (des)conhecimento ideológico. In: ZIZEK, Slavoj (Org.). Um mapa da ideologia. Rio de Janeiro: Contraponto, 1996. p. 143-52.

Semântica e discurso: uma crítica à afirmação do óbvio. Tradução de Eni P.

Orlandi. 3. ed. Campinas: Ed. UNICAMP, 1997.

. Papel da memória. In: ACHARD, Pierre et al. Papel da memória. Tradução de José Horta Nunes. Campinas: Pontes, 1999. p. 49-57.

. O discurso: estrutura ou acontecimento. 3. ed. Campinas: Pontes, 2002.

RAMAL, Andrea Cecília. Educação na cibercultura: hipertextualidade, leitura, escrita e aprendizagem. Porto Alegre: Artmed, 2002.

ROMÃO, Lucília Maria Sousa. Na teia eletrônica, fragmentos da memória. In:

MORELLO, Rosângela. (Org.). Giros na cidade: materialidade do espaço. Campinas: LABEURB/NUDECRI- UNICAMP, 2004a.

Nós, desconhecidos, na grande rede. Linguagem em (Dis)curso, Tubarão, SC, v. 5, 2004b. Disponível em: <http://www3.unisul.br/paginas/ensino/pos/linguagem/ 0501/04.htm>. Acesso em: 17 abr. 2009.

De areia e de silício: as tramas do discurso no livro eletrônico. Revista de

Estúdios Literários Especulo, Madrid, n. 31, nov. 2005. Disponível em:

<http://www.ucm.es/info/ especulo/ numero31/silicio.html>. Acesso em: 17 abr. 2009.

O cavalete, a tela e o branco: introdução à autoria na rede eletrônica. Delta,

São Paulo, v. 22, n. 2, 2006. Disponível em: <http://www.scielo.br/pdf/delta/v22n2/ a04v22n2.pdf>. Acesso em: 17 abr. 2009

Heterogeneidade e memória: o sujeito na trama de vozes alheias. In: ROMÃO, Lucília Maria Sousa; GASPAR, Nádea Regina. (Orgs). Discurso midiático: sentidos de memória e arquivo. São Carlos: Pedro \& João Ed., 2008. p. 95-112.

SANTAELLA, Lúcia. Navegar no ciberespaço: o perfil cognitivo do leitor imersivo. São Paulo: Paulus, 2004.

SILVA, Obdália Santana Ferraz. Nos labirintos da web: possibilidades de leitura e produção textual nos cenários digitais. 2006. 202 f. Dissertação (mestrado) Universidade do Estado da Bahia, Salvador. 2006. Disponível em: $<$ http://www.dominiopublico. gov.br/pesquisa/DetalheObraForm.do?select_action=\&co_obra=130489>. Acesso em: 10 jul. 2009. 
WERTHEIM, Margaret. Uma história do espaço: de Dante à Internet. Tradução de Maria Luiza X de A. Borges. Rio de Janeiro: Ed. Jorge Zahar, 2001. 